\title{
NON-REACTIVE TUBERCULOSIS
}

\author{
BY \\ J. R. O'BRIEN \\ From the Portsmouth and Isle of Wight Pathological Service
}

(RECEIVED FOR PUBLICATION JANUARY 21, 1953)

Non-reactive tuberculosis has been reported under many different names. It is called acute caseating tuberculosis by Rich (1944), while on the Continent it is most commonly called Landouzyschekrankheit and the Yersin type of tuberculosis. It may be defined as a fatal form of tuberculosis in which many organs contain miliary foci of necrosis surrounded by normal parenchymal cells. Typically cellular response is completely absent, but occasionally there is a poor response of the usual type. Very large numbers of tubercle bacilli are found in and around these lesions. Usually in life there are gross abnormalities of haemopoiesis, such as anaemia or polycythaemia, agranulocytosis or a leukaemoid change, and thrombocytopenia. Rarely, the histological picture of non-reactive tuberculosis is found in leukaemia and myelosclerosis.

It is proposed to review the literature of nonreactive tuberculosis, to describe eight unpublished cases, and to discuss the pathogenesis of this condition.

TABLE I

SIXTY-SIX REPORTED CASES

\begin{tabular}{|c|c|c|c|c|}
\hline \multicolumn{4}{|c|}{ Clinical Diagnosis } & \multirow[b]{2}{*}{$\begin{array}{r}\text { No. } \\
22 \\
7 \\
5 \\
2 \\
6 \\
5 \\
13 \\
5 \\
1\end{array}$} \\
\hline $\begin{array}{l}\text { Agranulocytosis } \\
\text { Leukaemoid } \\
\text { Panmyelophthisis } \\
\text { Polycythaemia . . } \\
\text { Normal blood picture } \\
\text { No record of blood } \\
\text { Leukaemia } \quad . \\
\text { Myelosclerosis . . } \\
\text { Hodgkin's disease }\end{array}$ & $\begin{array}{l}\cdots \\
\cdots \\
\cdots \\
\cdots \\
\cdots \\
\cdots\end{array}$ & $\begin{array}{l}\cdots \\
\cdots \\
\cdots \\
\cdots \\
\cdots \\
\cdots \\
\cdots\end{array}$ & $\begin{array}{l}\cdots \\
\cdots \\
\cdots \\
\cdots \\
\cdots \\
\cdots \\
\cdots\end{array}$ & \\
\hline Tot & & $\ldots$ & $\ldots$ & 66 \\
\hline
\end{tabular}

There are sixty-six cases in the literature which fulfil the criteria of non-reactive tuberculosis. Table I shows the number of cases subdivided according to various haematological changes. A pre-existing disease process may influence the course of the tuberculous infection; accordingly, the 19 cases with leukaemia, myelosclerosis, and Hodgkin's disease have been isolated in the table. Forty-seven cases remain in the main group.
Other cases are often quoted, but they will not be considered as they are unacceptable for the following reasons: Weichmann (1922), Róth (1929), Holzer (case 2, 1927), and Reiche quoted by Bálint (1925) give no histological description. The cases of Reilly and Bolin (1931) and Loeschcke (1932) were newborn infants and were probably cases of transplacental infection.

The salient features of the 47 cases in the main group are summarized in Table II.

TABLE II

SUMMARY OF CASES REVIEWED WITH NO INTERCURRENT DISEASE

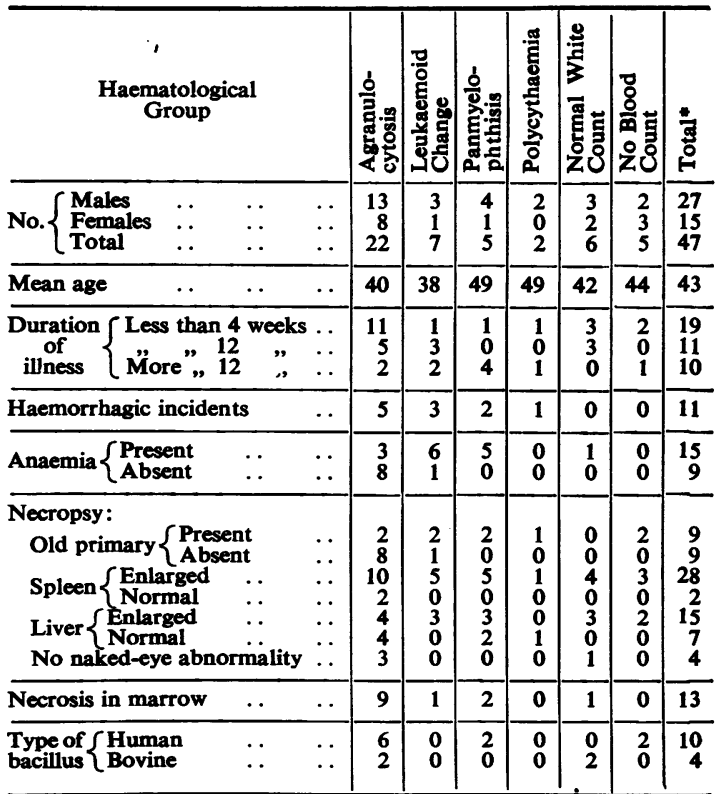

In places in the table the number of cases in some of the subdivisions does not add up to the total number of cases in the particular group. This is due to an absence of the relevant information in some of the papers.

\section{Clinical Course of Reported Cases}

The commonest course seems to have been an acute, overwhelming infection. Less often the syndrome presented as a chronic pyrexia of 
unknown origin (Siegmund, 1939, case 6), sometimes as an obscure anaemia, or apparently as panmyelophthisis (Arends, 1950) or as primary agranulocytosis. The terminal phase of the syndrome may be complicated by tuberculous involvement of many organs. The skin sensitivity to tuberculin was investigated only three times. Twice it was weakly positive (Gibson, 1946; Arends, case 2, 1950), and once negative (Hegler, 1938).

\section{Post-mortem Appearance}

It is remarkable that the post-mortem examination in four cases revealed splenomegaly, but no other macroscopic change suggestive of tuberculosis. In the other 27 cases, in which lesions were described, they varied from pinhead size up to yellow areas of necrosis of $1 \mathrm{~cm}$. in diameter. The spleen was nearly always reported as enlarged, while the liver was often enlarged. The glands often showed large necrotic or caseous areas (Pagel and Woolf, 1949; Smith, case 1, etc., 1949), but more usually they were normal. An old primary focus has been reported nine times, but several workers, particularly Siegmund (1939), have stressed its absence; he found no primary in seven of the nine cases in which a reasonably thorough search appears to have been made for a primary lesion. Lastly, there are several reports of tuberculous infection in a large number of organs. There is one notable exception to this list. No case of tuberculous meningitis has been reported.

\section{Histology}

The characteristic histological appearance was a small area of necrosis, sometimes with the "ghost" parenchymal architecture still just visible. Appropriately stained sections showed enormous numbers of acid-fast bacilli packed together forming felt-like masses. Surrounding this area were normal parenchymal cells, but no inflammatory or other foreign cells. This lesion is described in the majority of reports (for example, in the photomicrographs of Arends), but in quite a number of cases there was a mild degree of lymphocytic or monocytic cuffing (Gibson, 1946). Gibson (1946), Holzer (1927), and others have found evidence in some areas of a more or less normal tissue response with a lymphocytic cuff, epithelial cells, and young fibre formation. In all the cases accepted the atypical aspect of the body response has been stressed or clearly described, but in some cases there was also a response intermediate in form between the typical non-reactive lesion and that in the normal tissue.

The non-reactive lesions were always found in the liver and spleen. They were almost always present in the marrow. In the leukaemoid cases the marrow was usually very cellular; indeed, in these cases only the absence of leukaemic cellular infiltration in the spleen and liver made possible the exclusion of a diagnosis of leukaemia. Other reports (Marzullo and de Veer, 1931; Blair and Pagel, 1947; Custer and Crocker, 1932) have described a hypocellular and even fibrotic marrow. Commonly foci are found in the lungs and kidneys, but any organ, except, it seems, the meninges, may occasionally be similarly affected.

\section{Bacteriology and Mycology}

Coincidental mycelial infection was reported in four cases (Siegmund, case 3, 1939; Esser, 1926; Smith's cases 2 and 4,1949 ). The type of tubercle bacillus was identified by adequate cultural methods and animal inoculations in $\mathbf{1 4}$ cases. It was found to be human in 10 cases and bovine in four.

\section{Blood Changes}

Agranulocytosis.-Of the 47 cases now under discussion, 22 had leukopenia, or a total absence of polymorphs (Leibowitz, 1938; Marzullo and de Veer, 1931; Smith, case 3). Anaemia was not a feature. Thrombocytopenia was present in the few cases in which the platelets were counted, and was almost always associated with purpura. When investigated, the marrow was usually hypoplastic.

Leukaemoid Count.- In the seven cases accepted as having a leukaemoid blood picture, the total white count varied from 200,000 (Custer and Crocker, case 1,1932 ) to 4,000 (Gardner and Mettier, 1949; Leibowitz, 1938; Staffurth and Spencer, 1950), but all had a high proportion of blast cells or myelocytes (Custer and Crocker, case 1, 1932) or prolymphocytes (Staffurth and Spencer, 1950) or even monoblasts (Gibson, 1946). Clinically, these patients survived on average a little longer than those with agranulocytosis, and they had splenomegaly and anaemia and haemorrhagic incidents more frequently.

Panmyelophthisis.-Four cases included are under the heading of panmyelophthisis, all of which had thrombocytopenia, granulopenia, and anaemia, which was extreme in two. Haemorrhagic incidents were reported in two cases (Arends, case 1, 1950; Kernohan, 1950). Otherwise the clinical course in these few cases did not differ from that of the whole group.

Polycythaemia.-Two cases (Rennen, 1922; Lederer, 1923) were thought clinically to have polycythaemia. Both had over $7.5 \mathrm{~m}$. red cells per c.mm. and one (Rennen) had a high normal white count, with $90 \%$ polymorphs and an occasional nucleated red cell. 
Normal Blood Count.-In six cases the total white count was within normal limits, and the differential count when given was also normal. One of these cases had previously been diagnosed as having pernicious anaemia, but was having adequate treatment at the time of his final illness (von Wyss, case 5, 1940).

No Blood Count Reported.-Five cases are included in which the blood was not investigated, but which are acceptable since an adequate histological description was given.

Leukaemia.-In all the cases referred to so far the diagnosis of leukaemia could be excluded with reasonable certainty. Thirteen cases, most of which undoubtedly had leukaemia, will now be reviewed. A summary of the outstanding features in the cases of leukaemia, myelosclerosis, and Hodgkin's disease is presented in Table III. When the

TABLE III

SUMMARY OF CASES REVIEWED WITH INTERCUR RENT DISEASE

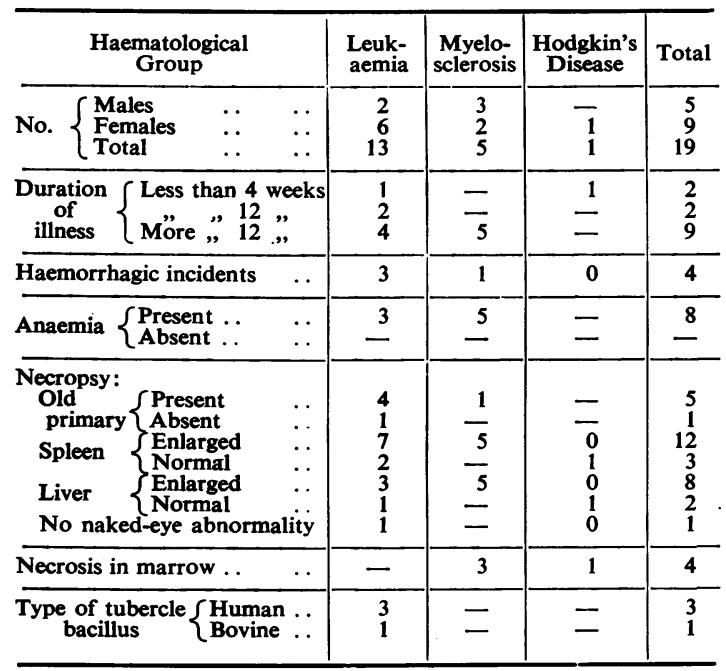

differential diagnosis between leukaemia and a leukaemoid change was in doubt, the cases have been included. Coley and Ewing's case (1911) probably had acute lymphatic leukaemia. Chronic myeloid leukaemia was present in seven cases, while lymphoblasts were found in one case (Fischer, 1935, case 1).

The course of the leukaemia seems to have been in no way abnormal, while that of the tuberculosis was usually rapid. In four out of five cases in which there was relevant information, there was evidence of old tuberculosis. The histological picture of the non-reactive tuberculosis was typical except that if there was any cellular response the cell type was that of the leukaemia.
Myelosclerosis.-There are two reports of this histological picture occurring in people dying with myelosclerosis (Carpenter and Flory, 1941; Crail, Alt, and Nadler, 1940). In each case the myelosclerosis had been present for many months. Crail et al. report four cases associated with non-reactive tuberculosis and contrasts these with five other cases of idiopathic myelosclerosis. His tuberculous patients were all comparatively young and all were febrile; the duration of the illness was shorter than that in the idiopathic group. He suggests that in these cases the tuberculosis first stimulates the fibrosis of the marrow and the glands and subsequent development of splenomegaly and the leuko-erythroblastic blood picture, with terminal haematogenous spread and the production of non-reactive lesions

\section{Present Series}

Case 1.-H. B., a man aged 33, complained of bleeding gums, a petechial rash, and haematuria. The only abnormal findings were some changes in the mid-zone of the left lung in the radiograph of the chest, a platelet count of 5,000 per c.mm., and a prolonged bleeding time. He was given a pint of fresh blood and improved clinically and the platelet count rose to 200,000 per c.mm. in 10 days. Forty-three days later he complained of wasting, vomiting, abdominal pain, and loose stools. A radiograph of the chest and platelet count were normal. The stools contained many acid-fast bacilli. The patient died 110 days after his original symptoms. The bacillus isolated from the stools was cultured by Dr. A. Q. Wells and found to be a normal human type tubercle bacillus of high virulence. Post-mortem examination showed an emaciated man weighing $45 \mathrm{~kg}$. Small miliary tubercles were visible in many organs. There was a small area of consolidation in the midzone of the left lung about $4 \mathrm{~cm}$. in diameter. The intestines showed gross tuberculous rlceration, while the portal glands were frankly caseous. The spleen $(592 \mathrm{~g}$.) was firm and had a finely granular appearance.

The histological appearances are those of miliary tuberculosis, but are remarkable for three reasons. There is necrosis rather than caseation. There are very many tubercle bacilli within the epithelioid and giant cells and lying free in the tissues. Fibrosis is minimal and the cellular reaction consists chiefly of polymorphs, most of which are degenerate. Epithelioid systems are not uncommon, but the cellular reaction generally is poor. The lungs show tubercles of varying ages as well as areas with necrosis with no tisslie response. The spleen is packed with miliary non-reactive tubercles. There are tubercles in many other organs.

This man succumbed to miliary tuberculosis and tuberculous enteritis with a histological picture very like that of the non-reactive type nearly four months after an acute episode of thrombocytopenic purpura. The portal of entry was presumably the lung. It should be emphasized that the white cells were 
numerically and morphologically normal throughout his illness.

Case 2.-F. I. N., a woman aged 59 years, began to lose weight and felt vaguely unwell 11 months before her death. These symptoms were slowly progressive. Pallor, fever, and an enlarged spleen were noted three months before her death. The haemoglobin was then $58 \%(8.6 \mathrm{~g} . \%)$. The white cells varied between 1,000 and 2,500 per c.mm. while the differential count was normal and remained so throughout her illness. The platelet count was 70,000 per c.mm. Two sternal punctures showed marked hypocellularity with normal red and white cell maturation. The Westergren sedimentation rate was 60 to $120 \mathrm{~mm}$. in one hour. She was given 3 pints of blood. The fever and wasting increased. The spleen enlarged to the brim of the pelvis. She died undiagnosed 11 months after the onset of symptoms, having pursued an apparently smooth course downhill with increasingly rapid deterioration towards the end.

Permission was given for a partial necropsy only. The spleen had a-normal cut surface. The liver and mesenteric glands appeared to be normal. Histology of the liver and spleen showed vast numbers of tubercle bacilli matted into clumps, but the surrounding architecture was not disorganized (Figs. 1 and 2). Clumps of up to 15 bacilli could also be found inside normal liver cells and others were lying free in the sinuses. The absence of any inflammatory response or fibrosis was remarkable in both organs. Similar, but fewer, lesions were found in the marrow.

There is no definite evidence to indicate when the non-reactive tuberculous process began. Three months before death she had fever, splenomegaly, and granulopenia and the course of her illness throughout was a smooth one. Perhaps a chronic tuberculous infection in some organ not examined was responsible for most of her illness, but it seems more likely that the whole course was associated with a non-reactive type of lesion.

Case 3.-E. E., aged 25, became ill four months after his wife died of pulmonary tuberculosis, when he complained of pain in the chest, a productive cough, and night sweats. Seven weeks before his death a large pleural effusion was found. He became increasingly ill, breathless, and febrile. His sputum was repeatedly examined, but tubercle bacilli were seen only a few days before his death. A culture of the sputum, taken three weeks before death, grew M. tuberculosis. Three blood investigations may be selected as typical of many (see Table in next column).

The report on the sternal puncture by Dr. J. C. White emphasized the overwhelming white cell preponderance. Granulocytes at all stages of maturation were present, but some were morphologically abnormal. The few red cell precursors were normal. He considered this appearance compatible with subacute myeloid leukosis or leukaemoid reaction.

At necropsy the liver, spleen, and lungs showed numerous miliary tubercles. The lungs also showed

\begin{tabular}{|c|c|c|c|}
\hline Days Before Death & 43 & 5 & 1 \\
\hline 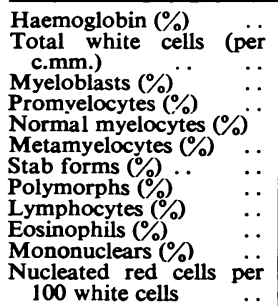 & $\begin{array}{c}82 \\
32,000 \\
2 \cdot 5 \\
2 \cdot 5 \\
30 \\
\frac{22}{24} \\
12 \cdot 5 \\
\frac{6}{6} \cdot 5 \\
-\end{array}$ & $\begin{array}{r}82,000 \\
1 \\
2 \\
26 \\
14 \\
25 \\
25 \\
5 \\
1 \\
1 \\
-\end{array}$ & $\begin{array}{r}15,000 \\
1 \\
1 \\
1 \\
11 \\
37 \\
50 \\
8 \\
1\end{array}$ \\
\hline
\end{tabular}

nodules of caseous bronchopneumonia from 1 to $4 \mathrm{~cm}$. in diameter. Some thoracic lymph nodes showed early caseation. The femoral marrow looked normal.

In the marrow there are a few scattered tubercles which consist of an area of necrosis containing a few epithelioid cells and nuclear remnants, but no giant cells. The tubercles in the liver are typically non-reactive with no surrounding tissue reaction whatever. No leukaemic deposits are present (Fig. 3). The spleen is riddled with tubercles consisting of necrotic areas with much nuclear debris, a few lymphocytes and epithelioid cells and a very few spindle cells, probably fibroblasts. The lung shows miliary lesions and massive confluent foci of acute necrosis. An occasional small collection of lymphocytes is the only cellular response. Sections, stained six years after death by the Ziehl-Neelsen method, do not show any tubercle bacilli.

Infection probably occurred six months before death and the lung was the probable seat of the primary infection or reinfection. The clinical picture was that of pulmonary tuberculosis and the leucocytosis was considered clinically in life to be a leukaemoid response to infection. Inspection of Figs. 3 and 4 shows that the tissue reaction approaches to a slight degree that found normally. As the causative organism was seen and cultured during life, it is curious that it cannot now be demonstrated in the sections.

Case 4.-M. R., a woman aged 54, gave a history of three years' illness with pulmonary tuberculosis, haemoptysis, and a pleural effusion which was repeatedly aspirated. Two months before death she suddenly experienced severe upper abdominal pain, subsequently found to be due to a large subcapsular haemorrhage in an infarcted area of the spleen. Examination revealed a large mass extending from the left ribs to the umbilicus and a just palpable liver. Repeated blood examination showed $6.7 \mathrm{~m}$. red cells per c.mm.; haemoglobin, 14.0 g. $\%$; packed cell volume, $57 \%$; platelets, 350,000 per c.mm.; total white count, 30,000 per c.mm. (neutrophil polymorphonuclear leucocytes $85 \%$, lymphocytes $12 \%$, monocytes $3 \%$ ). A very occasional myelocyte and nucleated red cell was also present. A sternal puncture produced an almost acellular smear with a differential count similar to that of the blood, but with the addition of about $10 \%$ of polychromatic normoblasts. 


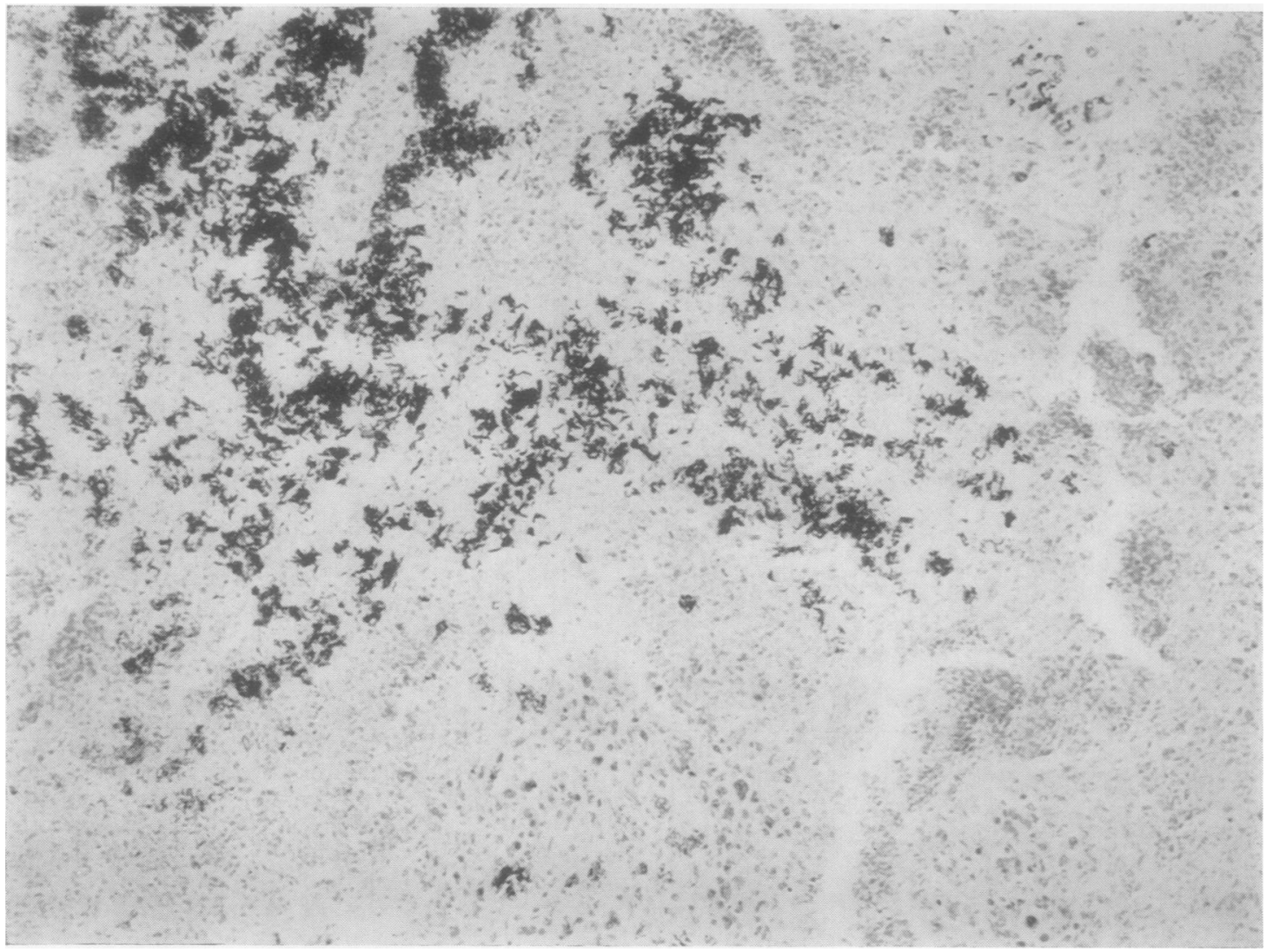

Fig. 1.-Spleen $(\times 200)$ stained by the Ziehl-Neelsen method, showing masses of tubercle bacilli and largely intact stroma with no tissue response.

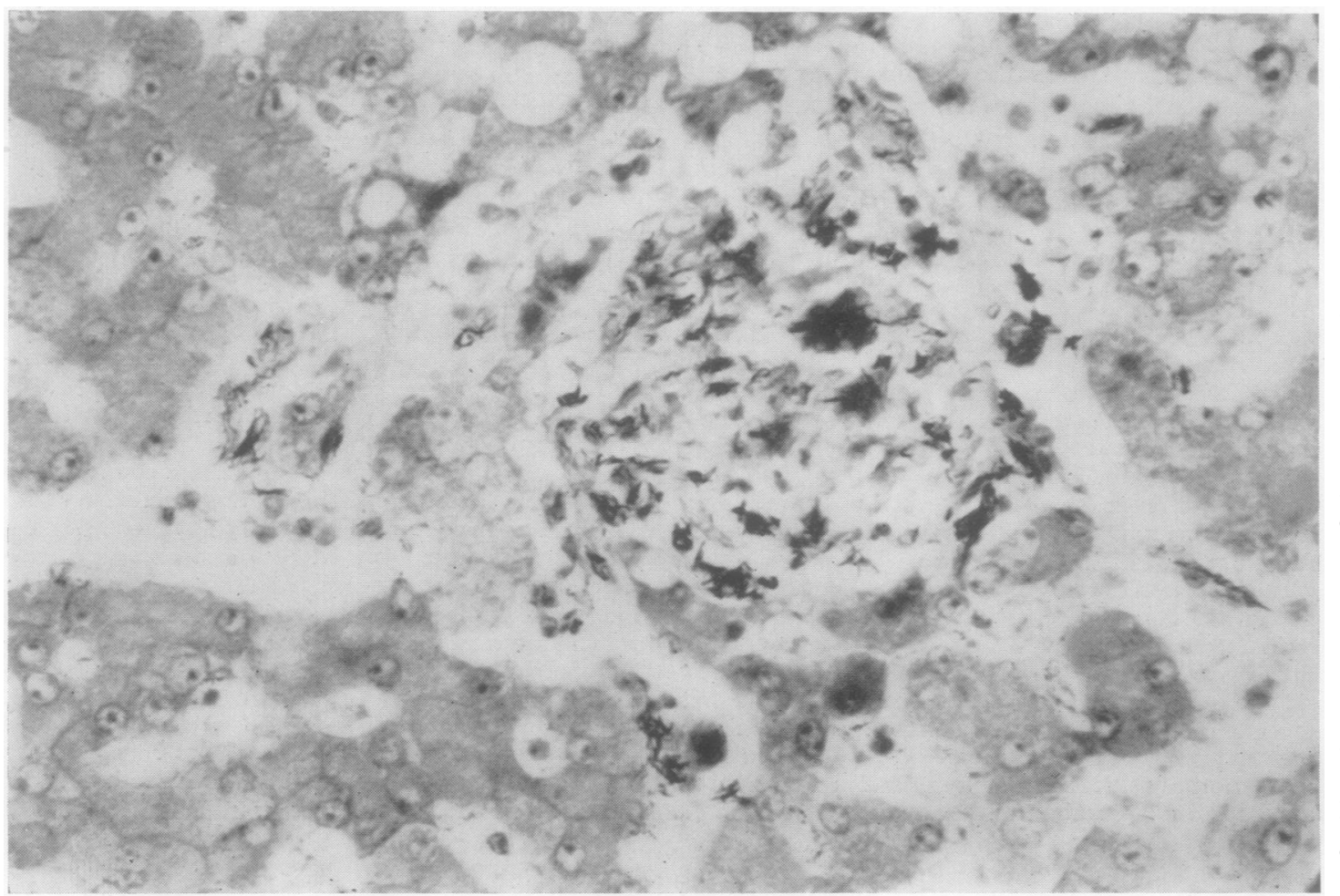
intact parenchymal cells. 


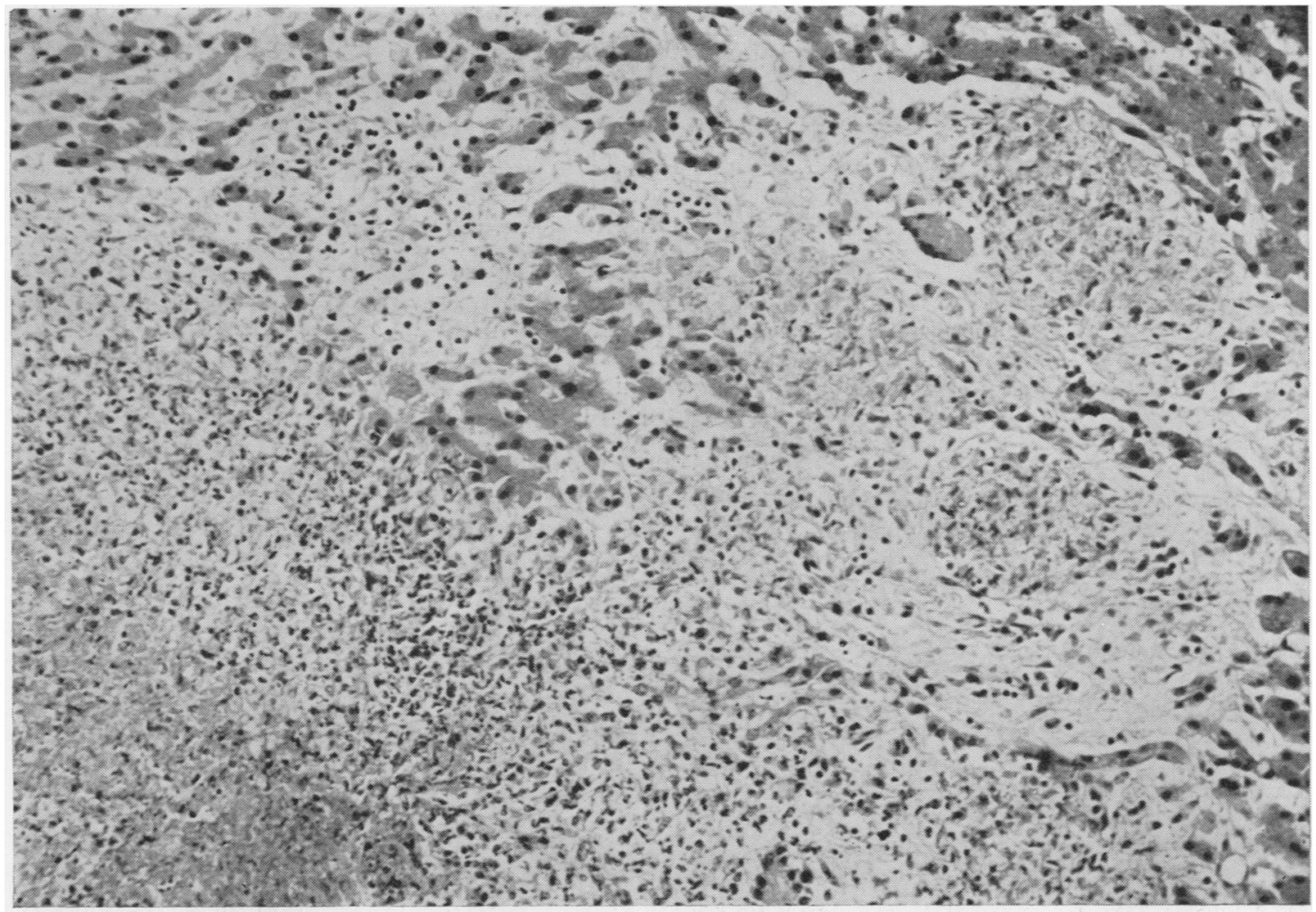

Fig. 3. Liver $(\times 200)$ stained by haematoxylin and eosin. The tissue response consists of an occasional giant cell and some lymphocytes: large numbers of nuclear fragments also present.

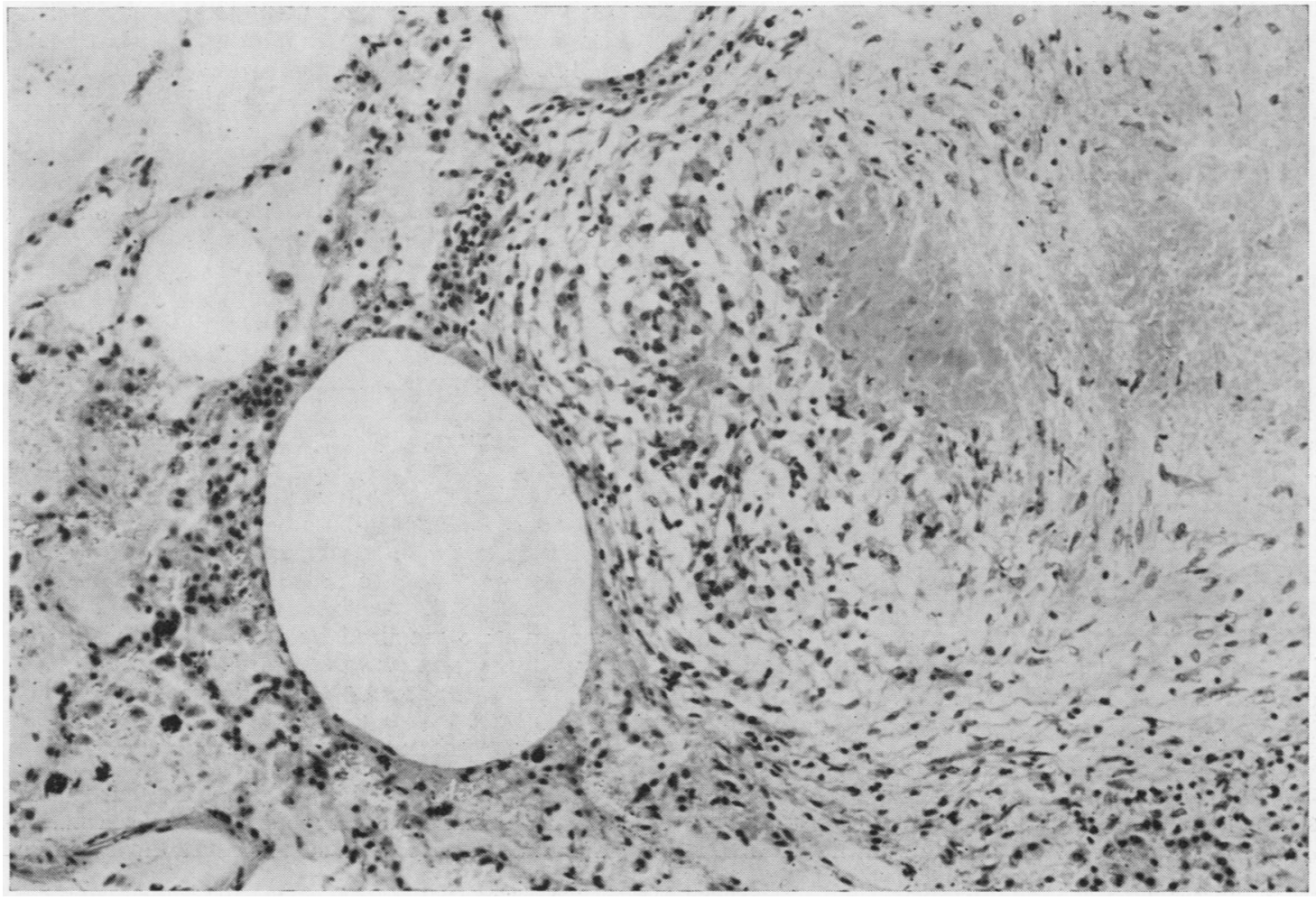

Fig. 4.-Lung $(\vee 200)$ stained with haematoxylin and eosin, showing necrotic area with only minimal lymphocytic cuffing and some nuclear debris only. 
This examination could not be repeated. No treatment was given and the patient improved considerably. Three days before her death she had repeated severe haemoptyses. She was then febrile, cachectic, and dying. A fixed fluctuant swelling had appeared over the left upper abdominal mass. A single blood examination showed haemoglobin 5.6 g. $\%$, reticulocytes 6 per 100 red cells, platelets 380,000 per c.mm., total white cells 100,000 per c.mm. (neutrophil polymorphonuclear leucocytes $89 \%$, lymphocytes $5 \%$, polychromatic normoblasts $6 \%$, no myelocytes seen). At necropsy the lungs were seen to be riddled with extensive bronchopneumonic spread of tuberculosis through all lobes with marked old cavitation and fibrosis. The small intestine contained two shallow ulcers extending horizontally round the gut, about three feet from its lower end. The spleen measured $30 \times 20 \times 18 \mathrm{~cm}$. with a large fluctuant subcapsular haematoma overlying an irregular wedge-shaped infarct.

No tubercles are seen in the liver or spleen. The spleen, and to a lesser extent the liver, is heavily infiltrated with polymorphs, but no necrotic foci are present. A mesenteric gland shows typical normal tuberculous caseation. The marrow from several places shows increased cellularity with a preponderance of granulocytes. There is neither sclerosis nor fibrosis nor is the picture that of leukaemia. In none of the organs described so far were acid-fast bacilli demonstrated.

The lungs everywhere showed gross disorganization with much caseation and fibrosis and a scanty cellular response of the normal type. In contrast, but often adjacent, were areas of necrosis full of nuclear debris with no surrounding cellular reaction, which contained very many acid-fast bacilli. Adjacent to one of these areas was a small blood vessel containing red cells and polymorphonuclear leucocytes. There were a number of acid-fast bacilli free in the lumen of the vessel and inside polymorphonuclear leucocytes.

Sections through the ulcers in the small intestine showed in some areas the normal tissue response to the infection and contained no acid-fast bacilli. Adjacent to these areas were a few quite different lesions with intense polymorphonuclear leucocytic infiltration, nuclear debris, and a few lymphocytes, giving the appearance of tiny abscesses. There were very many acid-fast bacilli in almost all these areas. Adjacent were a lymph vessel and a blood vessel, the latter partly occluded by a cellular thrombus, both of which contained considerable numbers of intravascular acid-fast bacilli.

This patient had chronic pulmonary tuberculosis, and for at least two months she also had gross splenomegaly and a high red and white cell count. These findings cannot be explained by any ordinary haematological diagnosis and it is remarkable that the picture should have been associated with histological evidence at death of non-reactive tuberculosis in some organs. After years of a normal response to a tuberculous infection which was slowly advancing, the body's defences were suddenly overwhelmed, but in an unusual fashion.
The following four cases, very kindly given to me by Dr. F. B. Smith, were presented by him to the Association of Clinical Pathologists in 1949, but have not been previously published.

Smith : Case 1.-A man, aged 59, was admitted with generalized purpura and clinically was suspected of having typhoid fever. Clinical details are now lacking. His illness lasted for about one month. The total white cells numbered 3,000 per c.mm., but there was no record of the differential count.

At necropsy there was a thick exudate on the fauces and pharyngeal wall suggesting agranulocytosis. The pleural cavities were obliterated by old fibrous adhesions. The lungs appeared normal. The liver was slightly enlarged and contained sparse, ill-defined, small, pale yellow foci. The spleen was not enlarged and contained a few similar foci. The mesenteric glands were soft and matted together and contained fine miliary foci suggesting an acute tuberculous process.

The small foci in the liver, spleen, and portal glands showed necrosis with a complete absence of surrounding tissue response. They were packed with large numbers of acid-fast bacilli resembling $M$. tuberculosis.

This case appears to be a good example of acute typho-tuberculosis as it is described in the German literature.

Smith: Case 2.-A man, aged 52, became ill one month before his death. One week before death he was in a drowsy typhoid state with an intermittent rash, bleeding gums, and purpura. Repeated blood examination showed a haemoglobin of $75 \%$, a total white count from 1,000 to 3,200 per c.mm. with only 500 to 800 polymorphs per c.mm. His condition steadily deteriorated until his death.

At necropsy an old scar from an empyema drainage wound was noted. The pharynx and fauces were extensively ulcerated. There were old fibrous adhesions in the right pleural cavity. The lungs contained small haemorrhagic foci. The liver $(1,700$ g.) and spleen (420 g.) contained small and inconspicuous pale yellow foci. A few small ulcers were present in the duodenal mucosa. A single tracheal gland was moderately enlarged. The marrow in the femur was essentially normal.

The liver, spleen, gland, and marrow showed miliary areas of necrosis with no tissue reaction containing acidfast bacilli, occasionally in very large numbers. In the marrow bacilli were seen both in the necrotic areas and lying free among the normal marrow cells. There were some miliary necrotic foci in the lungs, which contained no acid-fast bacilli. Sections of these areas and of the duodenum were examined by Dr. J. T. Duncan, who confirmed the presence of mycelia and spores, and considered, in the absence of culture confirmation, that both sites were probably infected with monilia and that the lungs were infected with aspergillus as well.

Smith : Case 3.-A spinster, aged 65, four months before death had a macrocytic anaemia with a haemoglobin of $56 \%$, and histamine-fast achlorhydria. The 
total white cell count was constantly about 1,000 per c.mm. until her death and there were usually only 100 polymorphs per c.mm. while almost all the other cells were lymphocytes. There was no response to intensive liver therapy. A sternal puncture showed hypoplasia of the marrow with a gross preponderance of immature granulocytes. She was transfused, but relapsed. She was transfused again and the haemoglobin remained at $80 \%$ until death. One month before death she became febrile for the first time and irrational. She died after a slowly progressive illness lasting 10 months.

Necropsy showed a liver of normal size and a slightly enlarged spleen with, in both organs, scanty, inconspicuous miliary foci similar to those seen in the last two cases. Sections of the liver, spleen, and tracheal glands showed miliary, and occasionally confluent, areas of necrosis. These areas contained nuclear remnants, but with no surrounding cellular reaction. Large numbers of acid-fast bacilli were seen in all three sites.

This patient, with a 10 months' history, again raises the question of when she was infected with the tubercle bacillus. Was it a month before her death when she became febrile, or had she been infected from the beginning ?

Smith : Case 4.-W. M. J., a man aged 45, had pleurisy as a young man. Five months before his death he apparently had pneumonia, with a haemoptysis and later a small hydrothorax. He had intermittent fever, recurrent, severe, staphylococcal abscesses, and went slowly downhill. Blood examination showed a haemoglobin of 55 to $65 \%$; the total white cell count varied from 2,000 to 4,000 per c.mm. with 14 to $28 \%$ eosinophils. Sternal puncture showed hypoplasia of the granulocytic series. M. tuberculosis was not isolated in life. Post-mortem material was sent to Dr. A. Q. Wells, who grew and identified normal $M$. tuberculosis of human type. Monilia was repeatedly found in the sputum and mycelia were also present. These were identified culturally from post-mortem material by Dr. J. T. Duncan as Aspergillus fumigatus.

At necropsy the lungs showed a few small firm yellow nodules which contained the mycelia of aspergillus, but no tubercle bacilli. The spleen $(430 \mathrm{~g}$.) was dotted with white foci up to $3 \mathrm{~mm}$. in diameter. The tracheal and para-aortic glands were enlarged and firm. Sections of the spleen and glands showed the characteristic areas of non-reactive tuberculosis. Large numbers of tubercle bacilli were present in these sites.

Entry was presumably by the lungs. The clinical course was conspicuous for the frequency and severity of the pyogenic infections. Both this and the mycelial infection were presumably due to the lowered resistance of the patient associated with the leucopenia. The evidence is not sufficient to prove whether the tuberculosis or the agranulocytosis came first. The fact that his first complaint was pneumonia and haemoptysis suggests that pulmonary tuberculosis was the first lesion.

\section{Discussion}

Are there sufficient common trends in the cases reviewed and reported to justify the concept of a single disease process? Undoubtedly the tubercle bacillus is common to all, but the variation in the reaction of the host is considerable. No cases have been included that had a normal tissue response to tubercle, but many cases have some features of the normal reaction, at any rate in some of the lesions. It seems probable that there are cases in which the tissue reaction is intermediate between the normal and the non-reactive types and that the cases under discussion merely represent an extreme degree of one type of tissue response.

The Parasite.-From the time when this condition was first recognized until recently there have been suggestions (Yersin, 1888; Loewenstein, 1934) that the causative organism was an avian type of tubercle bacillus. In no case has there been conclusive experimental proof of this assertion, and there are now many reports in which the causal organisms were proved to be a tubercle bacillus of the normal human or bovine types.

The Host.-There is considerable evidence that the tubercle bacillus is not immediately harmful to the normal living mammalian cell. For example, in tissue culture experiments Brieger (1949) grew explants of uninfected animals and found that when these explants were infected with tubercle bacilli some of the bacilli were "phagocytosed and contained in the macrophages for long periods with all the signs of a perfect symbiosis." It also seems that no extract from the tubercle bacillus is lethal or even toxic when injected into the living uninfected animal as a single dose. It must be assumed, therefore, that the tubercle bacillus does not normally kill by the manufacture of a cellular poison. When bacilli grow in the body they liberate products of metabolism that are treated as foreign proteins by the body. It is the nature of the sensitivity response of the body as a whole that largely determines the nature of the local tissue response to the local liberation of an essentially bland foreign protein. The fate of the patient now depends chiefly on the balance struck between the local tissue defence and the response of the body as a whole to the products of the bacillus, i.e., its sensitivity.

Bloch (1950) infected animals with three-day-old cultures of bacilli containing a high cord-factor content. Fifty per cent. of these animals died in 14 days compared with a $50 \%$ survival rate for 32 days in identical animals injected with three-week-old cultures. These results may be explained in a 
manner differing from that put forward by Bloch himself. The three-day-old cultures are presumably growing logarithmically and producing from the moment they are injected large quantities of metabolic products. Normally the infecting dose is comparatively small, growth of the bacilli certainly is initially slow, and therefore the intensity and duration of the antigenic stimulus is different. It may be the time factors and the quantity but not the quality of the tuberculous products that produced the abnormal response in Bloch's mice.

In a normal person infected with tubercle there are few bacilli in the tissues and a vigorous local tissue response. One must assume that the sensitivity induced is the right kind to produce the vigorous local response. In non-reactive tuberculosis there are very large numbers of bacilli and no tissue response and therefore it seems very probable that the nature of the induced sensitivity is different.

The suggestion is therefore put forward that in human non-reactive tuberculosis it is the rate of liberation, or the quantity of the products of metabolism of the tubercle bacillus, that evoke a state of abnormal sensitivity in the patient. Alternatively or additionally, it is suggested that these people are in an abnormal state and cannot produce a normal sensitivity response.

An almost identical histological lesion occurs in voles (Wells and Robb Smith, 1946) infected naturally with the murine type of $M$. tuberculosis in an illness which, incidentally, may last several months. Similar appearances are also found in rats and mice infected intravenously.

The histological appearances of the lesions in transplacentally infected human babies are often similar. Two features of this infection seem to differentiate it from adult primary infection. First, the infection is blood-borne from the start and the dose is probably heavy, and secondly, and probably more significantly, the mechanism for the production of antibodies is imperfect in the neonatal period.

In some patients treated with cortisone for some quite different disease an unsuspected tuberculous lesion has advanced rapidly. The histology of these lesions is strikingly like that found in naturally occurring non-reactive tuberculosis. It appears that the probable explanation in these patients is that the mesenchyme cannot proliferate and differentiate in response to an appropriate stimulus. The histological appearance may in any case be attributed to paralysis of the primitive mesenchymal cell, and this explanation is supported by the observations that other stimuli of widely differing character cannot stimulate a response of the mesen- chyme in animals treated with cortisone (Sissons $\underset{\vec{\rho}}{\vec{P}}$ and Hadfield, 1951).

The association of non-reactive tuberculosis with $\frac{\bar{C}}{\partial}$ true leukaemia, which is usually chronic, is so $\frac{\bar{c}}{\frac{1}{6}}$ frequent relative to the total number of reported $\mathbb{\otimes}$ cases of non-reactive tuberculosis that it cannot be explained by chance. In these cases it must be ${ }^{\infty}$ assumed that the leukaemia develops first and $\vec{\circ}$ predisposes to this type of tissue response if the $\overrightarrow{\vec{\omega}}$ subject becomes infected with tubercle. Siegmund ${ }_{\sigma}^{\omega}$ (1939) maintains that this type of lesion can occur only in a primary infection or in a second primary infection when the patient has antigenically $\omega$ completely recovered. Reference to Tables II, III, $\underset{\sim}{\sim}$ and the case reports show that in at least eight cases ${ }^{\circ}$ in the non-leukaemic groups and in all five of the $\stackrel{\circ}{\circ}$ leukaemic cases there was good evidence of an old $\overrightarrow{ }$ active tuberculous infection.

Duration.-The histological appearance of non- $\frac{\mathrm{C}}{\mathrm{c}}$ reactive tuberculosis suggests an acute process, but ${ }_{-}^{+}$ many of the patients dying with non-reactive tuber- $\mathscr{G}$ culosis have been ill for months. It has already? been mentioned that voles may survive with this histological picture for some months before they succumb. Clearly in most cases the non-reactive nature of the tuberculous lesion will only be estab-® lished at death and so its duration must be sur- $\stackrel{\otimes}{\propto}$ mised. The indirect evidence suggests that it may $\overrightarrow{\vec{P}}$ exist in man for some months.

Abnormalities of the Blood.-All but five of the reported cases of non-reactive tuberculosis in which? a count was carried out had some disproportion of haematopoiesis. Arends (1950) has claimed that: the common factor in non-reactive tuberculosis 3 is an abnormality of the blood, and that this predisposed to an abnormal tissue response. The occurrence of this type of lesion in leukaemia, and possibly in myelosclerosis and Hodgkin's? disease, in which the polymorphs are known to be abnormal, is then easily explained. There are, however, cases of non-reactive tuberculosis in which the polymorphs and all the other types of $\mathrm{N}$ cell have remained normal throughout the course of the illness. Blood changes vary considerably ${ }_{\sigma}^{\omega}$ and are most unlikely to be the cause of the abnormak tissue reaction, although this possibility cannot be을 excluded. There are, therefore, two possibilities. $\$$ They may be brought about by the mechanical presence of the bacilli and the areas of necrosis in the marrow, but examination of the marrow shows that a very high proportion of the total volume of $\frac{\mathbb{P}}{\mathbb{D}}$ marrow is still histologically normal, so this explana-음 tion seems unlikely. The second possibility is a? direct action of the products of metabolism of the tubercle bacillus on the marrow. It is now suggested 
that the marrow cells are in a state of abnormal sensitivity, in a manner somewhat similar to the abnormal state already postulated for the cells of the other organs, and that it is this abnormal sensitivity of the body that explains the coincidence of non-reactive tissue response and the abnormal blood picture.

Aronson (1931) showed that tuberculin has a specific cytotoxic action on tissue cultures of the marrow and other tissues from infected animals and that the same small dose of tuberculin was innocuous to tissues from healthy animals. This work was largely confirmed by Moen and Swift (1936). Sensitivity of this type might explain the cases of agranulocytosis. Feldman and Stasney (1937) established experimentally that under certain conditions the products of metabolism of tubercle bacilli stimulated granulocytosis and produced a leukaemoid blood picture. The difference between stimulation and inhibition, particularly in this field of sensitivity, is probably slight, and the paradox of agranulocytosis and leukaemoid changes occurring in the same disease process may not be so improbable as first appeared.

This suggestive ambivalence of the reaction of the marrow to the products of tubercle bacilli finds some support in the work of Smith (1951) on the meninges. When she injected tuberculin intrathecally in cases of tuberculous meningitis, usually a violent cellular reaction with an outpouring of polymorphonuclear leucocytes was produced. In those patients who were Mantoux-negative no response was obtained.

\section{Summary}

Non-reactive tuberculosis is defned as a histological condition in which there are miliary areas of necrosis containing large numbers of tubercle bacilli surrounded by normal parenchymal cells or a minimal degree of the usual tissue response. There are 66 acceptable reports of this condition in the literature which is reviewed. The clinical course of the disease is most varied. It may be that of a rapidly overwhelming, typhoid-like illness or it may apparently continue for many months.

Its association with an abnormal blood picture is striking. Agranulocytosis, obscure anaemias, leukaemoid changes, and thrombocytopenia are frequent, and the condition is also found in patients with chronic leukaemia.

Eight previously unpublished cases are reported.

The mechanism of the abnormal tissue response and its association with an abnormal marrow response is discussed in the light of recent experimental work.
For permission to publish these cases I have to thank those doctors under whom they were admitted, namely, Professor L. J. Witts for Case 1, Dr. G. R. Steed and Dr. S. Noy Scott for Case 2, Dr. Nellan and Dr. J. C. White for Case 3, and Dr. W. A. Lister and Mr. G. L. Preston for Case 4.

I am also most grateful to Dr. F. B. Smith for permission to publish for the first time the four cases he presented to the Association of Clinical Pathologists in 1949; one of these, Smith Case 4, was actually investigated by Dr. H. G. Close, to whom I am also indebted. I also have to thank Professor T. F. Hewer's Department of Pathology for the photomicrographs.

I also am glad to acknowledge the kindness and help of Dr. E. M. Brieger, Professor G. Hadfield, Professor T. F. Hewer, Dr. R. G. MacFarlane, Professor Dorothy Russell, and Dr. A. Q. Wells.

\section{Addendum}

Since this paper was prepared, Friend and Thackerary (1952) have reported four cases of the association of tuberculosis and hepatosplenomegaly with an abnormal blood count. One case had typical non-reactive lesions. It has not been included in the tables.

\section{REFERENCES}

Arends, A. (1950). Acta med. scand., 136, 417.

Aronson, J. D. (1931). J. exp. Med., 54, 387.

Balint, R. (1925). Wien. Arch. inn. Med., 10, 165.

Blair, E. J., and Pagel, W. (1947). Tubercle, Lond., 28, 115.

Bloch, H. (1950). J. exp. Med., 92, 507.

Brieger, E. M. (1949). Tubercle, 30, 227, 242.

Carpenter, G., and Flory, C. M. (1941). Arch. intern. Med., 67, 489.

Coley, W. B., and Ewing, J. (1911). Trans. Ass. Amer. Phys., 26, 178.

Crail, H. W., Alt, H. L., and Nadler, W. H. (1940). Blood, 3, 1426.

Custer, R. P., and Crocker, W. J. (1932). Folia Haemat., Lpz., 46, 359.

Esser, A. (1926). Beitr. Klin. Tuberk., 63, 699.

Feldman, W. H., and Stasney, J. (1937). Amer. J. med. Sci., 193, 28.

Fischer, W. (1935). Beitr. Klin. Tuberk., 87, 334.

Gardner, F. H., and Mettier, S. R. (1949). Blood, 4, 767.

Gibson, A. (1946). J. Path. Bact., 58, 469.

Hegler, O. (1938). Dtsch. Arch. klin. Med., 183, 1.

Holzer, K. (1927). Beitr. Klin. Tuberk., 66, 245.

Kernohan, R. J. (1950). Brit. med. J., 2, 399.

Lederer, K. (1923). Wien. Arch. inn. Med., 5, 23.

Leibowitz, S. (1938). Arch. Path., Chicago, 25, 365.

Loeschcke, H. (1932). Beitr. Klin. Tuberk., 81, 171.

Loewenstein, E. (1934). Schweiz. med. Wschr., 64, 808.

Marzullo, E. R., and Veer, J. A. de (1931). Amer. J. med. Sci., 182, 372 .

Moen, J. K., and Swift, H. F. (1936). J. exp. Med., 64, 339.

Pagel, W., and Wolf, A. L. (1949). Amer. Rev. Tuberc., 59, 311.

Reilly, W. A., and Bolin, Z. E. (1931). Amer. J. Dis. Child., 41, 582

Rennen, K. (1922). Beitr. Klin. Tuberk., 53, 197.

Rich, A. R. (1944). The Pathogenesis of Tuberculosis. Thomas, Springfield, Illinois.

Roth, N. (1929). Beitr. Klin. Tuberk., 71, 634.

Siegmund, H. (1939). Beitr. path. Anat., 103, 431.

Sissons, H. A., and Hadfield G. J. (1951). Demonstration: International Congress of Clinical Pathologists, London.

Smith, F. B. (1949). Presidential Address to Association of Clinical Pathologists, England.

Smith, H. (1951). Personal communication.

Staffurth, J. S., and Spencer, H. (1950). Blood, 5, 1161. Wells, A. Q., and Robb-Smith, A. H. T. (1946). Spec. Rep. Ser.
med. Res. Coun., Lond., No. 259. H.M.S.O., London.

Wiechmann, E. (1922). Med. Klin., 18, 1086.

Wyss, W. H. von (1940). Helv. med. Acta, 7, 430.

Yersin, A. (1888). Ann. Inst. Pasteur, 2, 245. 